\title{
World Journal of

\section{Determining the optimum medium voltage level by analysis of different voltage levels}

\author{
Fatma AVLI FIRIŞ ${ }^{*}$, AKEDAS Electricity Distribution A.Ş., Kahramanmaras, Turkey \\ Suggested Citation:
}

AVLI FIRIŞ, F. (2020). Determining the optimum medium voltage level by analysis of different voltage levels. World Journal of Environmental Research. 10(2), 37-49 https://doi.org/10.18844/wjer.v10i2.5344

Received from August 10, 2020; revised from October 21, 2020; accepted from December 25, 2020;

Selection and peer review under responsibility of Assoc. Prof. Dr. Murat Sonmez, Middle East Technical

University, Northern Cyprus Campus, Cyprus.

(C)2020 Birlesik Dunya Yenilik Arastirma ve Yayincilik Merkezi. All rights reserved

\begin{abstract}
Electric energy, which is the main input of the growing world economy, depending on the consumption of the rapidly increasing world population and the devices fed with this energy, have become more indispensable in our lives with each passing day. In the consumption of electrical energy, determining the voltage level plays an important role in planning distribution systems that will directly affect consumers. Distribution systems in our country have been established at different levels for technical and financial reasons. Incorrect choices that can be made during the determination of the voltage level in distribution systems may increase energy unit costs and network losses, and may cause insulation and reliability problems. The aim of this study is to determine the optimum voltage level in distribution systems. A pilot region was determined for a local electricity distribution network in our country, and modeling and analysis were carried out at different voltage levels in the region with the help of a numerical analysis program. According to the results achieved, Insulation and reliability problems at low voltages are few and economic in terms of investment costs, but it has been observed that the operating load and cost are high due to high network losses. In high voltages, although the operating burden and cost are relatively low, it has been observed that the investment costs are high and the isolation and reliability problems are high.
\end{abstract}

Keywords: cost; distribution; investment; operating ;Voltage

* ADDRESS FOR CORRESPONDENCE: Fatma AVLİ FIRIŞ, AKEDAS Electricity Distribution A.Ş., Kahramanmaras, Turkey 


\section{Introduction}

After the electrical energy is produced in the power plants, it is increased to the transmission levels by means of step-up transformers, also called the step-down centre from the load distribution centres through energy transmission lines [1]. It is brought to transformer centres in cities. These lines terminating at transformer centres are connected to load points in the city network, which is called the transformer post. In other words, the voltage of the energy transported by transmission lines to consumption areas at long distances is first reduced to medium voltage and then to low voltage by transformers, and then distributed. For this, low voltage and medium voltage networks are required. In high voltages in our country, While $380 \mathrm{kV}, 154 \mathrm{kV}$ and $66 \mathrm{kV}$ levels are used, there are values in two stages, $380 \mathrm{~V}$ and $220 \mathrm{~V}$ in low voltage. The medium voltage level, which acts as a bridge between high voltage and low voltage, is in the stages of $6.3 \mathrm{kV}, 10 \mathrm{kV}, 15 \mathrm{kV}, 30 \mathrm{kV}, 33.5 \mathrm{kV}, 66 \mathrm{kV}$ and is an indispensable requirement of an electricity distribution network.

Electricity distribution costs are facility setup costs that can be defined as fixed costs and operating expenses that can be defined as variable costs [2] . Facility setup costs depend on the installation power of the facility and the materials required for the establishment of the facility, assembly etc. includes expenses. Operational expenses include expenses arising from varying values such as losses that occur depending on the amount of energy drawn from the network during the operation of the facility. The planning of the system of the distribution network is of great importance in order to provide the customers with high quality, uninterrupted and reliable electricity. Planning mistakes to be made in system installation can cause the system to be under pressure and reduce system reliability. For this reason, millions of investments are made every year in electricity distribution systems and it is aimed to meet the increasing energy demands at the optimum level [3] .These investments generally; It comes to the fore as expansion, improvement, maintenance, repair, renewal investments and R\&D studies. When planning electricity distribution systems, these systems

- Having standard material,

- Low investment cost and fast return,

- Having N-1 criteria,

- Easy to operate and maintain,

- Stability of the network voltage,

- Short breakdown and power outage time,

- Low technical and non-technical losses,

- Low SAIDI and / or SAIFI quality criteria,

- The situation and structure will not change for many years in the future,

It is required to meet the criteria. In addition, the main goal of the laws and regulations is to distribute the electricity to the end user in a quality, uninterrupted and cheap way. Here, the main responsibility falls on the institutions and organizations performing electricity distribution duties. However, these investments are not sufficient considering the socioeconomic structure and expansion in cities. For this reason, distribution system planning is made in MV and LV networks of distribution companies. Shortand long-term master plans are prepared, and network expansion is made.

Designs and analyses of the electricity distribution network are made based on the technical knowledge and experience of the engineers in practice [4]. However, the costs of the distribution network cover approximately $45 \%$ of all energy network costs. For this reason, network expansion and renewal analysis should be done with precision. A design to be made considering minimum cost and maximum efficiency will also contribute greatly to the country's economy. Distribution network design, network power, 
conductor cross section, transformer characteristics, voltage drop, etc. is made by considering the factors that will affect the power flow and voltage drop. Distribution network costs are divided into two parts as fixed costs and variable costs [5] . Fixed costs in the distribution network, location of the distribution transformer centre, step down center location, material, assembly, iron losses, etc. and the location, material, assembly, etc. of the lines. It includes the initial investment costs, while variable costs include the copper loss cost in the distribution transformer and the lost energy cost of the line [6].

\section{Methodology}

\subsection{Analysis of Different Medium Voltage Levels}

DIgSILENT is short for "Digital Simulation of Electrical Networks". It is a program used for the analysis of transmission, distribution and industrial electrical systems and developed to achieve optimization goals in the planning and operation of these systems. The validity and accuracy of the results obtained through this program are the planning of power systems and This program also facilitates the control of many difficult and complex analysis on electrical systems such as load flow analysis, short circuit calculations, stability analysis, harmonic calculations, distance and overcurrent time protection, optimal load flow analysis, reliability analysis and distribution system analysis [7] .The purpose of load flow analysis performed in electrical power systems is to examine power flows, loads, busbar voltages in possible variable load situations. Also, many issues such as voltage spikes in busbars, loads on cables and transformers, power flows that may change direction, reactive power capacity of the generation facility can be followed [8].

The electricity distribution network in a region of Kahramanmaraş province was considered in order to carry out this study, which was carried out to determine the medium voltage level used in electricity distribution networks, in a sound manner. In addition to the existing network (154 kV / $31.5 \mathrm{kV}$ ), $154 \mathrm{kV}$ / $10.5 \mathrm{kV}, 154 \mathrm{kV} / 20 \mathrm{kV}$ and $154 \mathrm{kV} / 50$ in addition to the existing network, provided that the number of transformers and line length remain the same in order to determine the optimum medium voltage level in this pilot area. 3 (three) network models, including kV, have been made. Necessary modelling and analyzes were carried out by using the data obtained from the geographic information system and running the load flow analysis in the DIgSILENT Power Factory program. In the simulations of the load flow analysis in the DIgSILENT Power Factory program, the colours represent the voltage range and the varying voltage levels are shown with different colours. In the simulations, a colour scale varying at various intervals has been prepared in per unit according to the rates of voltage drop. In the simulations performed here, the green colour expresses zero loss, while the blue colour expresses the voltage drops, as the tone of the blue colour increases, the voltage drops increase.

\subsection{Modelling and Network Analysis for $154 \mathrm{kV} / 10.5 \mathrm{kV}$}

In the simulations performed here, the green colour expresses zero loss, while the blue colour expresses the voltage drops, as the tone of the blue colour increases, the voltage drops increase. In the simulation of transforming the current $34.5 \mathrm{kV}$ system to $10.5 \mathrm{kV}$ voltage with all elements; Although the voltage drops of the users close to the substation is not significant; It is observed that this value gradually increases as the distance to the transformer centre increases, and the users at the end of the network experience a voltage drop of $39 \%-40 \%$ of the voltage. In order to prevent this voltage, drop, 
approximately 3 new transformers centres or step-down centres are required to make gradual voltage drops.

\section{Results}

As can be seen from Fig 1, as a result of the application of a voltage of $10.5 \mathrm{kV}$ to the system, it is seen that there are voltage drops spread over large areas in the region. According to the colour scale, expressed here with the dark blue colour; 0.9 p.u. It is seen that there are voltage drops of up to $10 \%$, that is, it is not possible to say that these figures are at an acceptable level.

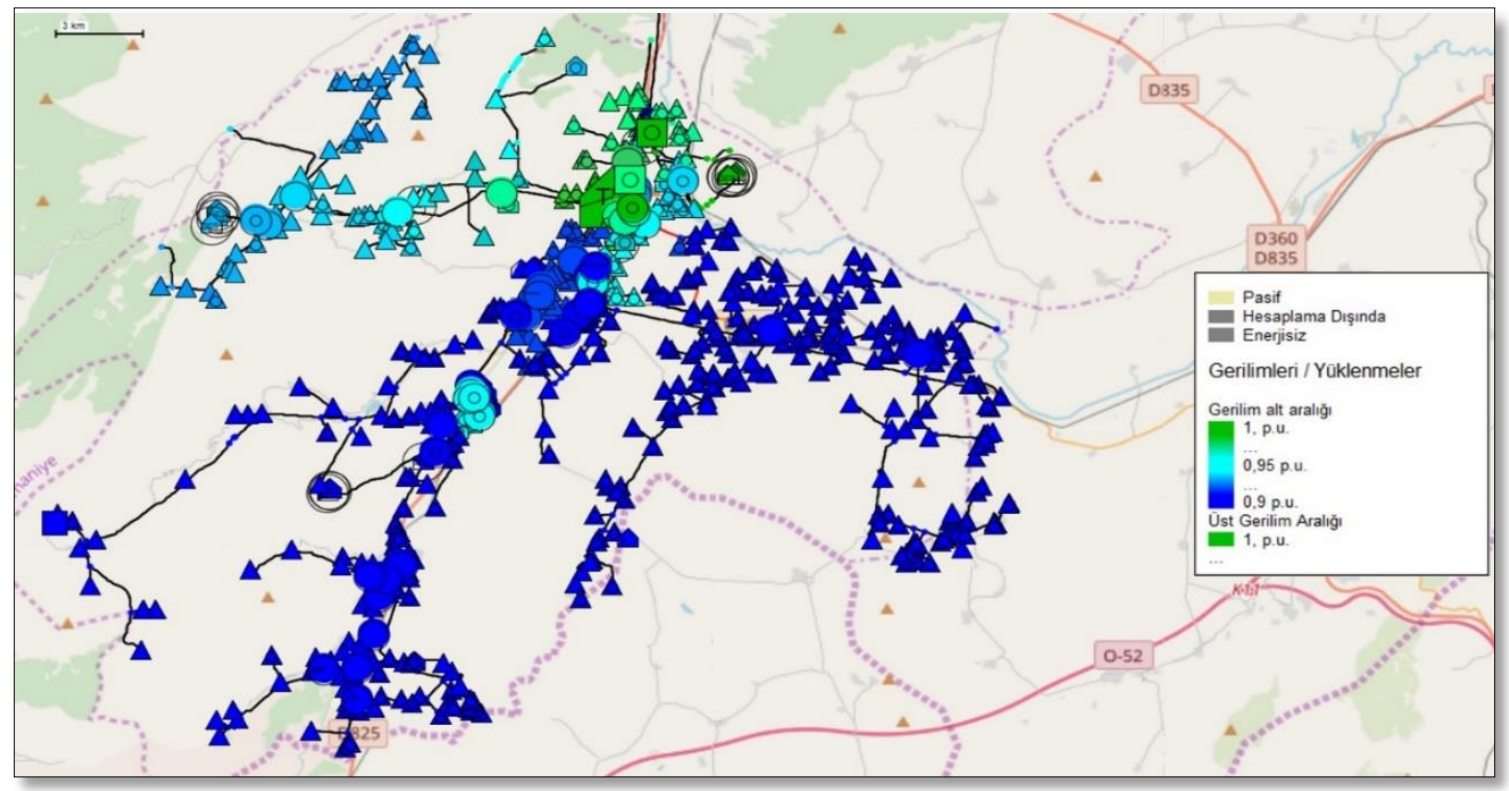

Figure 1.154 kV / 10.5 kV Simulation

In this case, the initial investment cost, spare material cost, operating cost, etc. Although the application of this voltage level does not pose a technical problem in the vicinity of the substation and / or stepdown centre, the technical losses of the lines increase gradually as the length of the network increases.

Table 1. Conductor costs in 10.5 kV Simulation [9]

\begin{tabular}{|c|c|c|c|}
\hline Line Type & $\begin{array}{l}\text { Weight } \\
\text { (KG) }\end{array}$ & $\begin{array}{c}\text { Unit price } \\
\text { (屯) }\end{array}$ & $\begin{array}{c}\text { Total cost } \\
\text { (も) }\end{array}$ \\
\hline Al_095 & 2855,00 & $€ 21,02$ & $€ 60.012,04$ \\
\hline Al_150 & 4385,73 & $€ 21,02$ & ६92.188,07 \\
\hline Al_400 & 8738,45 & $€ 21,02$ & €183.682,31 \\
\hline Cu_035 & 73,84 & $€ 47,81$ & Ł3.530,29 \\
\hline Cu_050 & 11658,37 & $€ 47,81$ & €557.386,84 \\
\hline Cu_070 & 171,20 & $€ 47,81$ & €8.185,25 \\
\hline Cu_095 & 42479,33 & $€ 47,81$ & €2.030.936,63 \\
\hline Cu_120 & 3075,97 & $€ 47,81$ & Ł147.062,16 \\
\hline Cu_150 & 7549,31 & $€ 47,81$ & €360.932,75 \\
\hline Cu_240 & 19975,07 & €7,81 & Ł955.008,07 \\
\hline Hawk & 40600,51 & $€ 20,40$ & $€ 828.250,33$ \\
\hline
\end{tabular}


AVLi FIRIŞ, F. (2020). Determining the optimum medium voltage level by analysis of different voltage levels. World Journal of Environmental Research. 10(2), 37-49 https://doi.org/10.18844/wjer.v10i2.5344

\begin{tabular}{|c|c|c|c|}
\hline Partridge & 671,82 & $€ 20,40$ & Ł13.705,11 \\
\hline Pigeon & 31387,87 & $€ 20,40$ & $€ 640.312,54$ \\
\hline Raven & 2687,73 & $€ 20,40$ & $€ 54.829,73$ \\
\hline Swallow & 44821,12 & $€ 20,40$ & €914.350,75 \\
\hline \multicolumn{2}{|c|}{ TOTAL AMOUNT } & \multicolumn{2}{|c|}{ €6.850.372,87 } \\
\hline
\end{tabular}

Table 2. Conductor costs in 10.5 kV Simulation [9]

\begin{tabular}{|c|c|c|c|}
\hline Transformer Type & Piece & $\begin{array}{c}\text { Unit price } \\
\text { (屯) }\end{array}$ & $\begin{array}{c}\text { Total cost } \\
(も)\end{array}$ \\
\hline $10,5 / 0,4 \mathrm{kV}-50 \mathrm{kVA}$ & 35 & €10.622,53 & €371.788,55 \\
\hline $10,5 / 0,4 \mathrm{kV}-100 \mathrm{kVA}$ & 64 & €13.392,37 & $€ 857.111,68$ \\
\hline $10,5 / 0,4 \mathrm{kV}-160 \mathrm{kVA}$ & 58 & €17.833,95 & €1.034.369,10 \\
\hline $10,5 / 0,4 \mathrm{kV}-250 \mathrm{kVA}$ & 37 & $€ 22.267,15$ & $€ 823.884,55$ \\
\hline $10,5 / 0,4 \mathrm{kV}-400 \mathrm{kVA}$ & 17 & €27.579,66 & も468.854,22 \\
\hline $10,5 / 0,4 k V-630$ kVA & 2 & $€ 37.938,03$ & $€ 75.876,06$ \\
\hline $10,5 / 0,4 \mathrm{kV}-1.000 \mathrm{kVA}$ & 2 & $€ 50.823,59$ & Ł101.647,18 \\
\hline $10,5 / 0,4 \mathrm{kV}-2.000 \mathrm{kVA}$ & 1 & €94.514,33 & €94.514,33 \\
\hline $10,5 / 0,4 \mathrm{kV}-2.500 \mathrm{kVA}$ & 1 & €106.813,12 & €106.813,12 \\
\hline $10,5 / 0,4 \mathrm{kV}-3.200 \mathrm{kVA}$ & 1 & €127.393,67 & €127.393,67 \\
\hline $10,5 / 0,4 \mathrm{kV}-3.600 \mathrm{kVA}$ & 1 & €154.973,33 & $€ 154.973,33$ \\
\hline $10,5 / 0,4 \mathrm{kV}-3.750 \mathrm{kVA}$ & 1 & €155.927,66 & €155.927,66 \\
\hline 154/10.5kV - 50 MVA & 1 & Ł2.074.959,88 & €2.074.959,88 \\
\hline 154/10.5kV - $100 \mathrm{MVA}$ & 1 & も4.149.919,75 & €.149.919,75 \\
\hline TOTAL AMOUNT & & & $€ 10.598 .033,08$ \\
\hline
\end{tabular}

In the tables given above, the cost that will arise when the voltage level of the network elements (transformer, cable, conductor) which is currently $34.5 \mathrm{kV}$ is converted to $10.5 \mathrm{kV}$ has been calculated. It is seen that the total transformer, conductor-cable conversion cost will be 17.448.405,95 (with 2019 EPDK unit prices).

These costs, considering the establishment of a new network, is less economical compared to high voltage levels. But it should not be forgotten that the network is available and operates at a voltage level of $34.5 \mathrm{kV}$ and therefore the above costs will be spent to transform the network and this conversion cost will be in addition to the initial investment cost; Only transformer and conductor costs are included in the account; building, insurance, cell, etc. It should be noted that the materials are not included. Conversion costs will increase even more if these costs are taken into account.

\subsection{Modelling and Network Analysis for $154 \mathrm{kV} / 20 \mathrm{kV}$}

In the simulation of converting the existing network to $20 \mathrm{kV}$ voltage with all its elements, although the voltage drops of the users who are close to the TM (transformer centre), it is not at a significant level. It is observed that this value increases gradually as the distance to the TM increases, and that the 
users at the end of the network experience a voltage drop of over $19 \%$ of the voltage. Although this ratio is half of the $10.5 \mathrm{kV}$ network, it exceeds the acceptable rates, at least 1 (one) new transformer centre or step-down centre is required to achieve gradual voltage drop in the various regions. In this case, the initial investment cost, spare material cost, operating cost, etc. By increasing the costs, energy unit costs will increase exponentially.

As can be seen from Figure 2 as a result of the application of a voltage of $20 \mathrm{kV}$ to the system, although it does not pose a technical problem near the substation and / or step-down centre in the region, it is seen that the technical losses of the lines increase gradually as the length of the network increases.

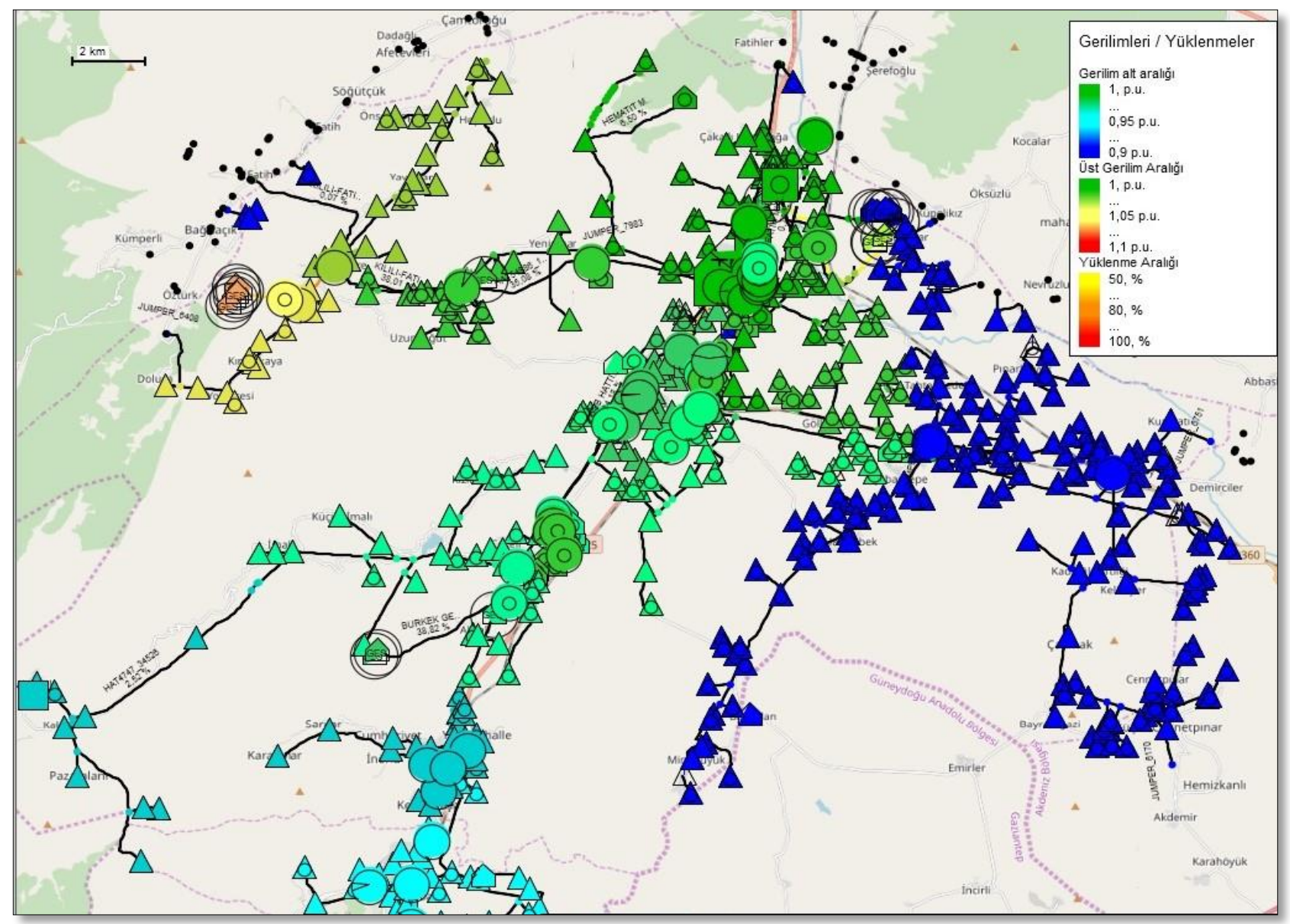

Figure 2. 154 kV / 20 kV Simulation

In Table 3 and Table 4, the cost that will arise when the voltage level of the network elements (transformer, cable, conductor), which is currently $34.5 \mathrm{kV}$, is converted to $20 \mathrm{kV}$ has been calculated. It is seen that the total transformer, conductor-cable conversion cost will be 17.448.405,95 EPDK unit prices). 
Table 3. Conductor costs in 10.5 kV Simulation [9]

\begin{tabular}{|c|c|c|c|}
\hline Line Type & $\begin{array}{l}\text { Weight } \\
\text { (KG) }\end{array}$ & $\begin{array}{c}\text { Unit price } \\
(\notin)\end{array}$ & $\begin{array}{c}\text { Total cost } \\
\text { (も) }\end{array}$ \\
\hline Al_095 & 2855,00 & $€ 21,02$ & $€ 60.012,04$ \\
\hline Al_150 & 4385,73 & $€ 21,02$ & €92.188,07 \\
\hline Al_400 & 8738,45 & $€ 21,02$ & €183.682,31 \\
\hline Cu_035 & 73,84 & $€ 47,81$ & $€ 3.530,29$ \\
\hline Cu_050 & 11658,37 & $€ 47,81$ & $€ 557.386,84$ \\
\hline Cu_070 & 171,20 & $€ 47,81$ & $€ 8.185,25$ \\
\hline Cu_095 & 42479,33 & $€ 47,81$ & €2.030.936,63 \\
\hline Cu_120 & 3075,97 & $€ 47,81$ & Ł147.062,16 \\
\hline Cu_150 & 7549,31 & $€ 47,81$ & $€ 360.932,75$ \\
\hline Cu_240 & 19975,07 & $€ 47,81$ & €955.008,07 \\
\hline Hawk & 40600,51 & $€ 20,40$ & $€ 828.250,33$ \\
\hline Partridge & 671,82 & $€ 20,40$ & €13.705,11 \\
\hline Pigeon & 31387,87 & $€ 20,40$ & $€ 640.312,54$ \\
\hline Raven & 2687,73 & $€ 20,40$ & $€ 54.829,73$ \\
\hline Swallow & 44821,12 & $€ 20,40$ & €914.350,75 \\
\hline \multicolumn{2}{|c|}{ TOTAL AMOUNT } & \multicolumn{2}{|c|}{$€ 6.850 .372,87$} \\
\hline
\end{tabular}

Table 4. Conductor costs in $20 \mathrm{kV}$ Simulation [9]

\begin{tabular}{|c|c|c|c|}
\hline Transformer Type & Piece & $\begin{array}{c}\text { Unit price } \\
\text { (も) }\end{array}$ & $\begin{array}{c}\text { Total cost } \\
\text { (も) }\end{array}$ \\
\hline 10,5/0,4kV- 50 kVA & 35 & €10.622,53 & $€ 371.788,55$ \\
\hline 10,5/0,4kV- 100 kVA & 64 & €13.392,37 & €857.111,68 \\
\hline $10,5 / 0,4 \mathrm{kV}-160 \mathrm{kVA}$ & 58 & €17.833,95 & Ł1.034.369,10 \\
\hline $10,5 / 0,4 \mathrm{kV}-250 \mathrm{kVA}$ & 37 & $€ 22.267,15$ & €823.884,55 \\
\hline $10,5 / 0,4 \mathrm{kV}-400 \mathrm{kVA}$ & 17 & $€ 27.579,66$ & €468.854,22 \\
\hline $10,5 / 0,4 \mathrm{kV}-630 \mathrm{kVA}$ & 2 & $€ 37.938,03$ & $€ 75.876,06$ \\
\hline $10,5 / 0,4 \mathrm{kV}-1.000 \mathrm{kVA}$ & 2 & $€ 50.823,59$ & €101.647,18 \\
\hline $10,5 / 0,4 \mathrm{kV}-2.000 \mathrm{kVA}$ & 1 & €94.514,33 & €94.514,33 \\
\hline $10,5 / 0,4 \mathrm{kV}-2.500 \mathrm{kVA}$ & 1 & Ł106.813,12 & €106.813,12 \\
\hline 10,5/0,4kV- $3.200 \mathrm{kVA}$ & 1 & €127.393,67 & €127.393,67 \\
\hline $10,5 / 0,4 \mathrm{kV}-3.600 \mathrm{kVA}$ & 1 & €154.973,33 & €154.973,33 \\
\hline $10,5 / 0,4 \mathrm{kV}-3.750 \mathrm{kVA}$ & 1 & も155.927,66 & €155.927,66 \\
\hline 154/10.5kV - $50 \mathrm{MVA}$ & 2 & €2.074.959,88 & \\
\hline 154/10.5kV - 100 MVA & 1 & も4.149.919,75 & €4.149.919,75 \\
\hline TOTAL AMOUNT & & & €10.598.033,08 \\
\hline
\end{tabular}

These costs are considering the establishment of a new network, it is less economical compared to high voltage levels. But it should not be forgotten that the network is available and operates at a voltage 
level of $34.5 \mathrm{kV}$ and therefore the above costs will be spent to transform the network and this conversion cost will be in addition to the initial investment cost.

In the account only transformer and conductor costs are included (building, insurance, cell, etc. It should be noted that the materials are not included. Conversion costs will increase even more if these costs are taken into account.

\subsection{Modelling and Network Analysis for $154 \mathrm{kV} / 50 \mathrm{kV}$}

In the simulation of converting the existing network to $50 \mathrm{kV}$ voltage with all its elements; As can be seen in Figure 3, if the network voltage is increased to $50 \mathrm{kV}$, it is seen that the voltage drop decreases considerably. While the voltage drop rates are close to $10.5 \mathrm{kV}$ and $34.5 \mathrm{kV}$ levels near the transformer centre, the value that increases as you move away from the transformer centre is lower than the low voltage levels. (Approximately $80 \%$ according to $10.5 \mathrm{kV}$ network, approximately $25 \%$ according to 34.5 $\mathrm{kV}$ network). Also, as a result of the increase in the current and voltage capacity, it is seen that the regions where the voltage drop is most experienced partially differ.

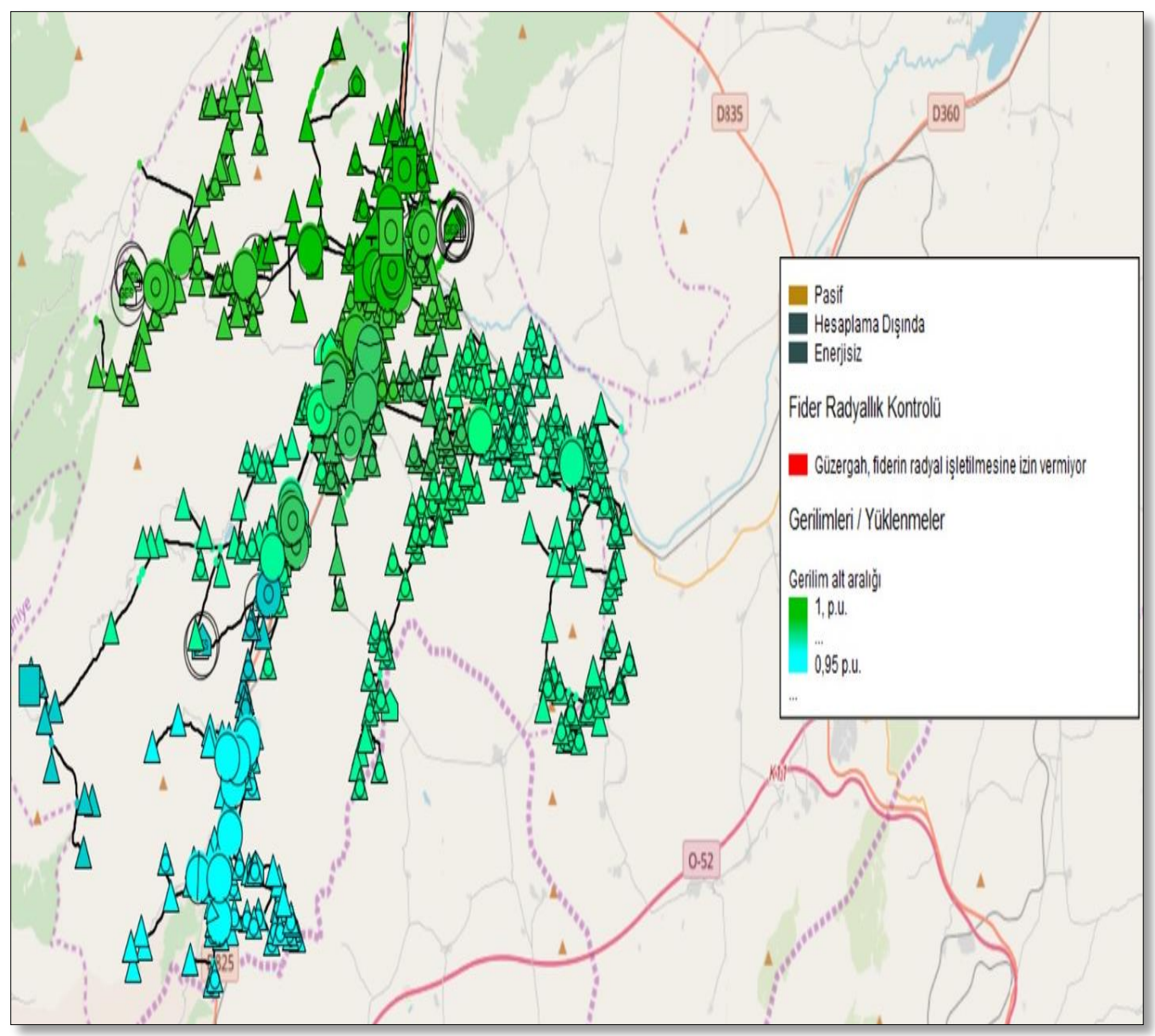

Fig 3. 154 kV / 50 kV Simulation 
Table 5. Conductor costs in 50 kV Simulation [Energy ]

\begin{tabular}{|c|c|c|c|}
\hline Transformer Type & Piece & $\begin{array}{c}\text { Unit price } \\
(€)\end{array}$ & $\begin{array}{c}\text { Total cost } \\
\text { (も) }\end{array}$ \\
\hline $50 / 0.4 k V-50$ kVA & 35 & €13.292,79 & $€ 465.247,65$ \\
\hline 50/0.4kV- 100 kVA & 64 & €15.826,95 & Ł1.012.924,80 \\
\hline 50/0.4kV- 160 kVA & 58 & $€ 20.544,33$ & Ł1.191.571,14 \\
\hline $50 / 0.4 k V-250$ kVA & 37 & $€ 25.369,35$ & €938.665,95 \\
\hline $50 / 0.4 \mathrm{kV}-400 \mathrm{kVA}$ & 17 & $€ 32.173,96$ & $€ 546.957,32$ \\
\hline $50 / 0.4 k V-630$ kVA & 2 & €42.697,13 & $€ 85.394,26$ \\
\hline $50 / 0.4 \mathrm{kV}-1000 \mathrm{kVA}$ & 2 & $€ 59.321,03$ & €118.642,06 \\
\hline 50/0.4kV- 2000 kVA & 1 & $€ 87.514,33$ & $€ 87.514,33$ \\
\hline $50 / 0.4 \mathrm{kV}-2500 \mathrm{kVA}$ & 1 & €103.813,12 & $€ 103.813,12$ \\
\hline 50/0.4kV- 3200 kVA & 1 & も157.601,09 & €157.601,09 \\
\hline $50 / 0.4 \mathrm{kV}-3600 \mathrm{kVA}$ & 1 & も167.721,83 & €167.721,83 \\
\hline 50/0.4kV- $3750 \mathrm{kVA}$ & 1 & €170.328,04 & €170.328,04 \\
\hline 154/50kV- 50 MVA & 1 & 2074959,875 & Ł2.074.959,88 \\
\hline 154/50kV- 100 MVA & 1 & 4149919,75 & も4.149.919,75 \\
\hline \multicolumn{3}{|c|}{ TOTAL AMOUNT } & $€ 11.271 .261,22$ \\
\hline
\end{tabular}

Table 5 shows the transformer costs in $50 \mathrm{kV}$ simulation. According to the Energy Market Regulatory Authority Unit Price Schedule, the prices of conductors / cables do not change according to the voltage level. The total cost of conductor-cable of the analyzed network is $€ 6,850,372,87$, and when it is collected with transformer costs, it is $18,121,634,09$. The difference is $673.228,14$ with the cost of $10.5 \mathrm{kV}$ network, the difference is 337.606 .57 ₹ with the cost of $34.5 \mathrm{kV}$ network.

\subsection{Modelling and Network Analysis for $154 \mathrm{kV} / 34.5 \mathrm{kV}$}

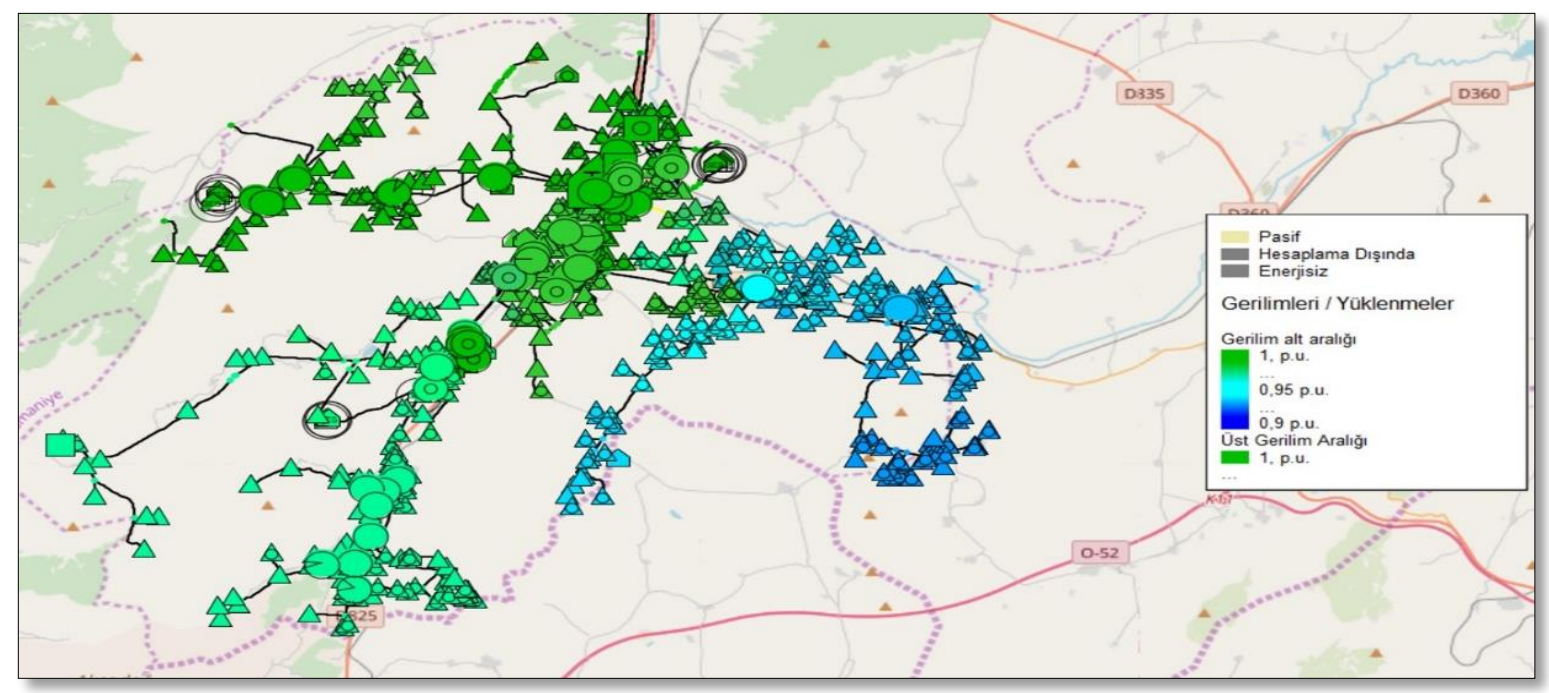

Figure 4. 154 kV / 34.5 kV Simulation 
Considering the voltage drop rates in the $34.5 \mathrm{kV}$ network; According to the $10.5 \mathrm{kV}$ network, both near the substation $(10.5 \mathrm{kV}-0.18 \%, 34.5 \mathrm{kV}-0.08 \%)$ and at the end points of the network $(10.5 \mathrm{kV}-39.8 \%$, $34.5 \%) \mathrm{kV}-6.8 \%$ ) is clearly seen to be quite low. Thanks to this situation, the need for a new substation and / or step down centre does not arise, and there is no cost-increasing situation.

Table 6. Conductor costs in 34.5 kV Simulation [9 ]

\begin{tabular}{|c|c|c|c|}
\hline Transformer Type & Piece & $\begin{array}{c}\text { Unit price } \\
\text { (も) }\end{array}$ & $\begin{array}{c}\text { Total cost } \\
\text { (も) }\end{array}$ \\
\hline $31.5 / 0.4 \mathrm{kV}-50 \mathrm{kVA}$ & 35 & Ł11.957,66 & €418.518,10 \\
\hline 31.5/0.4kV- 100 kVA & 64 & Ł14.609,66 & €935.018,24 \\
\hline 31.5/0.4kV- 160 kVA & 58 & も19.189,14 & Ł1.112.970,12 \\
\hline $31.5 / 0.4 \mathrm{kV}-250 \mathrm{kVA}$ & 37 & $€ 23.818,25$ & $€ 881.275,25$ \\
\hline 31.5/0.4kV- 400 kVA & 17 & Ł29.876,81 & $€ 507.905,77$ \\
\hline 31.5/0.4kV- 630 kVA & 2 & €40.317,58 & €80.635,16 \\
\hline 31.5/0.4kV- 1000 kVA & 2 & €55.072,31 & €110.144,62 \\
\hline 31.5/0.4kV- 2000 kVA & 1 & €85.348,44 & $€ 85.348,44$ \\
\hline $31.5 / 0.4 \mathrm{kV}-2500 \mathrm{kVA}$ & 1 & €100.486,51 & €100.486,51 \\
\hline 31.5/0.4kV- $3200 \mathrm{kVA}$ & 1 & €151.997,38 & €151.997,38 \\
\hline 31.5/0.4kV- $3600 \mathrm{kVA}$ & 1 & €161.347,58 & €161.347,58 \\
\hline 31.5/0.4kV- 3750 kVA & 1 & €163.127,85 & €163.127,85 \\
\hline 154/31.5kV- 50 MVA & 1 & Ł2.074.959,88 & Ł2.074.959,88 \\
\hline 154/31.5kV-100 MVA & 1 & も4.149.919,75 & も4.149.919,75 \\
\hline TOTAL AMOUNT & & & $€ 10.933 .654,65$ \\
\hline
\end{tabular}

Table 6 shows transformer costs in $50 \mathrm{kV}$ simulation. According to the Energy Market Regulatory Authority Unit Price Schedule, the prices of conductors / cables do not change according to the voltage level. The total cost of the conductor-cable of the analyzed network is $€ 6,850,372,87$, and when it is collected with the transformer costs, it is $17,784,027,52$ も. With $10.5 \mathrm{kV}$ and $20 \mathrm{kV}$ network costs, the difference is $335,621,57$ も.

\section{Discussion}

\subsection{Determining the Most Suitable Medium Voltage Level}

When making an energy distribution network plan, the purpose is; It is to be able to distribute the demanded power within the limits of acceptable reliability with minimum energy unit cost. The initial installation and annual operating costs of the transformer, line, and step down centre will vary depending on the demanded power and the level of distribution. The total power capacity needed by the region appears to be the main limiting parameter on the objective function. The number of transformer posts to be used and the line length are variables dependent on the power to be distributed.

In terms of initial investment cost, distribution from low voltage level seems to be a more economical choice for the first facility because the material price is cheaper. However, low-voltage distribution costs 
increase due to the need for additional distribution and investment for expansion in regions with rapidly increasing energy demand and distribution diameter [10] [11]. For configurations of $10.5 \mathrm{kV}$ and $20 \mathrm{kV}$, a substation or step down centre is required as an extra cost. With the inclusion of this cost item, the systems of $10.5 \mathrm{kV}$ and $20 \mathrm{kV}$ lost their economy in terms of transformer cost. Low-level, two-stage configurations, which had a cost advantage even though the download centre was included in the past, do not have this advantage over single-stage high-level configurations in today's technology and market conditions. This disadvantage should be added to the difficulty of operation and the high number of losses. Different transformer loss rates occur within a year in distribution systems. When all three voltage levels are examined; It was observed that the most transformer loss occurred at the level of $10.5 \mathrm{kV}$ and the least transformer loss at the level of $50 \mathrm{kV}$. There is a difference of approximately $2 \%$ between transformer losses of $50 \mathrm{kV}$ and $34.5 \mathrm{kV}$ levels. These transformer losses, together with the line losses, constitute the operating cost of the system. Although it may seem like a small difference compared to the initial investment costs, the total of this difference in operating expenses over time will affect the configuration choice. The same is true for line losses. Since the application is not a comparison of the newly designed regions but a transformation study, the operating level has been increased without changing the line cable types and cross sections. The higher the voltage level, the lower the line losses significantly, so the operating expenses also decrease.

As the voltage level increases,

- The network becomes more operable. It is advantageous in terms of operation since the number of step-down centres and feeders will decrease at higher voltage. In addition, the simple radial distribution arrangement preferred in the feeder structure also contributes to this situation.

- $\quad$ Power transfer capacity is increasing. The transfer capacity is proportional to the voltage, and when the voltage is doubled, the capacity will triple. Especially in regions with rapidly increasing energy demand, such a situation will be in favour of the grid as the need for capacity is inevitable.

- Distribution network diameter is also expanding, the amount of area where the distribution can be made increases in direct proportion to the level. Because the voltage drop is less.

- $\quad$ Power loss is decreasing. When the level is doubled, energy losses decrease by approximately $75 \%$.

- $\quad$ Since transmission will be made with cables of lower cross-section, financial advantage is provided in the selection of these materials.

- $\quad$ Energy cost is lower in high voltage distribution as line, transformer and step-down centre losses are reduced.

- $\quad$ Since the probability of failure in distribution systems is directly proportional to the length of the feeder, more frequent failures and longer fault clearing times occur at higher voltages. However, in today's technology, fault detection can be made faster and this disadvantage can be partially overcome.

- $\quad$ Since the area covered by the devices used in the region is more, it can cause economic difficulties especially in regions with high land value and dense population.

With the increase in power density due to the increase in the voltage level, the number of transformers for each of the four voltage levels and therefore the cost has increased. The higher the voltage level, the higher the cost, and it is seen that the most economical condition in terms of initial investment costs is $10.5 \mathrm{kV}$. However, additional substation and step-down centre costs have not been added to these costs. When these costs are added, it is seen that the economy decreases. With the increase in the load 
to be fed, total expenses increased and the cost per unit of energy varied. It is disadvantageous in terms of operating cost since generally more than one step is required at low voltage [12].

As a result of the analysis and calculations made; It has been determined that the $34.5 \mathrm{kV}$ level system can be realized with a lower investment compared to the $10.5 \mathrm{kV}$ level system with a lower investment than the development alternative, and it is more advantageous with the small number of step-down centres and feeder requirements, the simple radial distribution system in the feeder structure and the remote-control facilities it brings.

Electricity distribution networks reduces the electrical energy, which is reduced to medium voltage level with $380 \mathrm{kV}$ or $154 \mathrm{kV}$ energy transmission lines, to low voltage level in a single or double stage, to the consumption areas and ensure that it is delivered to the end users. This finding is supported by the research of [13], [14] . While it is low voltage used by end users and accepted up to $1 \mathrm{kV}$, the medium voltage concept is generally used in distribution systems with a voltage up to $52 \mathrm{kV}$ above $1 \mathrm{kV}$. Electricity distribution systems in our country have been established at different levels and levels for technical and financial reasons. Incorrect choices that can be made during the determination of the voltage level will increase the energy unit costs by causing high budget renewal, expansion, and conversion costs [15] [16] . On the other hand, it is critical to consider the energy losses of the system, the diameter of the distribution network that will grow due to the increasing demand, isolation, and reliability.

\section{Conclusion}

In this study conducted to determine the optimum medium voltage level in electricity distribution systems; A pilot area was determined for a local electricity distribution network in our country and modelling at different voltage levels was made on this region with the help of DIgSILENT Power Factory, a digital analysis program. The system, provided that the number of transformers and line lengths remain the same; The monitored voltage changes in each case were simulated by feeding from $10.5 \mathrm{kV}$, $20 \mathrm{kV}, 34.5 \mathrm{kV}$ and $50 \mathrm{kV}$ voltage levels. Voltage drops at low voltage levels have reached overly critical levels, and relatively improvements have been observed with the addition of one or more step-down centres.

One of the issues discussed within the scope of the study is the initial investment and operating costs of the system. At low voltage levels, it seems to be a more economical choice for the first facility, as the material price of the distribution equipment is cheaper in terms of initial investment costs. However, these costs may increase due to the need for additional distribution and investment for expansion in regions with rapidly increasing energy demand and distribution diameter. As the voltage level increases, even if the cost increases depending on the material prices, the energy cost in high voltage distribution is observed to be lower because the losses of line, transformer, and step-down centre decrease with high voltage.

According to the results achieved; the lower the voltage level, the lower the initial investment costs, however, the operating costs and burden are higher as network losses increase. When the voltage level rises, although the initial costs are high, the operating costs and load decrease. From another perspective, Insulation and reliability problems are at the lowest level in low voltage systems, and it is possible to say that these problems increase as the voltage level increases. 


\section{Acknowledgements}

\section{For Its Support, AKEDAŞ Electric Dağıtım A.Ş. We Owe Thanks To.}

\section{References}

[1] A. Trenten, "The use of smart transformer in the presence of dispersed generation", Diss. Politecnico di Torino, Torino, 19;90. Mar 2018.

[2] I. Rakhmonov, A. Berdishev, B. Khusanov, U Khaliknazarov. and U. Utegenov, "General characteristics of networks and features of electricity consumers in rural areas", In IOP Conference Series: Materials Science and Engineering (Vol. 883, No. 1, pp. 012104). IOP Publishing, 2020, July.

[3] M. Schiffer and G. Walther, "Strategic planning of electric logistics fleet networks: a robust location-routing approach", Omega, 1;80, pp. 31-42, Oct 2018.

[4] I. C. De los Rios and F. J. Charnley, "Skills and capabilities for a sustainable and circular economy: The changing role of design", Journal of Cleaner Production. 1;160, pp 109-12, Sep2017.

[5] M. Joos and I. Staffell, "Short-term integration costs of variable renewable energy: Wind curtailment and balancing in Britain and Germany", Renewable and Sustainable Energy Reviews, 86, pp. 45-65, 2018.

[6] L. Akbulut, "Electricity Distribution Network Optimization", Master's Thesis Electrical and Electronics Engineering Department Gazi University Institute of Science and Technology.

[7] Y. Sarıkaya and R. Yumurtacı, "Analysis of the effects of distributed generation resources on electricity distribution systems using the DIGSILENT power factory program", V. National Electrical Installation Congress and Exhibition, pp. 1-15, 2017.

[8] IEEE (2008). IEEE standard for interconnecting distributed resources with electric power systems. Application Guide For IEEE Std .. $1547^{\mathrm{Tm}}$.

[9] Energy Market Regulatory Authority, 2019 Unit Price Chart.

[10] A. Karaca, "Innovative technologies and living spaces; Updated living standards according to the evolution of homo sapiens", New Trends and Issues Proceedings on Advances in Pure and Applied Sciences, (12), pp. 91-108, 2020.

[11] E. Şenyiğit, "Transmission expansion planning under different uncertainties". New Trends and Issues Proceedings on Humanities and Social Sciences, 4(10), pp. 194-201, 2018.

[12] N. B. Si Ali, N. Benalia and N. Zerzouri, "Modelling and power control of grid connected wind energy system". Global Journal of Computer Sciences: Theory and Research, 8(1), pp. 14-23, 2018.

[13] H. Saboori, R. Hemmati, S. M Ghiasi, S. Dehghan "Energy storage planning in electric power distribution networks-A state-of-the-art review," Renewable and sustainable energy reviews. 1;79, pp. 1108-1121, Nov 2017

[14] D. Kaldiyarov, D. Nurmukhankyzy, A. Bedelbaeva, S. Kaldiyarov, O. Lemechshenko, and A. Baltabayeva, State modification and market mechanism for agroindustrial complex management in the region. International Journal of New Trends in Social Sciences, 2(1), pp. 01-08, 2018.

[15] G. Aquila, E. de Oliveira Pamplona, A. R. de Queiroz, P. R. Junior, M. N. Fonseca, "An overview of incentive policies for the expansion of renewable energy generation in electricity power systems and the Brazilian experience", Renewable and Sustainable Energy Reviews, 1;70:pp.1090-1098, Apr 2017.

[16] S. Baris, "Innovation and institutional quality: Evidence from OECD countries", Global Journal of Business, Economics and Management: Current Issues, 9(3), pp. 165-176, 2019. 